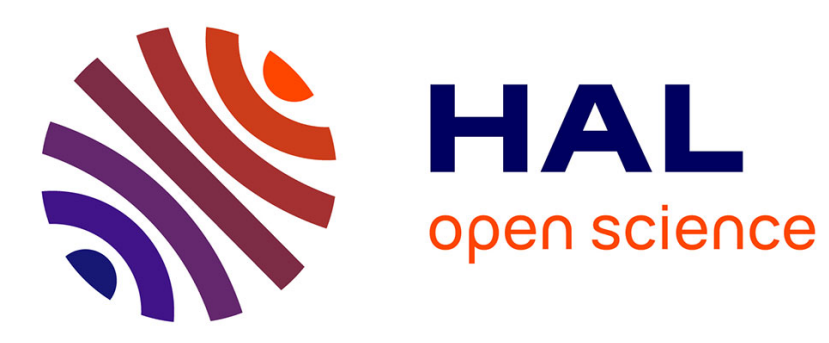

\title{
Key Performance Indicators Used as Measurement Parameter for Plant-Wide Feedback Loops
}

Charlotta Johnsson

\section{To cite this version:}

Charlotta Johnsson. Key Performance Indicators Used as Measurement Parameter for Plant-Wide Feedback Loops. IFIP International Conference on Advances in Production Management Systems (APMS), Sep 2014, Ajaccio, France. pp.91-99, 10.1007/978-3-662-44733-8_12 . hal-01387153

\section{HAL Id: hal-01387153 \\ https://hal.inria.fr/hal-01387153}

Submitted on 25 Oct 2016

HAL is a multi-disciplinary open access archive for the deposit and dissemination of scientific research documents, whether they are published or not. The documents may come from teaching and research institutions in France or abroad, or from public or private research centers.
L'archive ouverte pluridisciplinaire HAL, est destinée au dépôt et à la diffusion de documents scientifiques de niveau recherche, publiés ou non, émanant des établissements d'enseignement et de recherche français ou étrangers, des laboratoires publics ou privés.

\section{(c)(1)}

Distributed under a Creative Commons Attribution| 4.0 International License 


\title{
Key Performance indicators used as measurement parameter for plant-wide feedback loops
}

\author{
- Work in progress -
}

\author{
Charlotta Johnsson \\ Department of Automatic Control \\ Lund University, Lund, Sweden \\ charlotta.johnsson@control.lth.se
}

\begin{abstract}
Feedback is a fundamental concept in automatic control. Feedback loops are used extensively in industrial applications today and there are work-procedures for designing traditional single parameter control loops. In the work procedure it is important to select control-parameters, manipulated parameters and control-strategies. A similar work-procedure could also be used for designing plant-wide control feedback loops. Key performance Indicators is thus an important concept since they can be used as control-parameters. In this paper an analogy between the single-loop and plant-wide approach is discussed, and key performance indicators from the new international standard ISO 22400 are presented.
\end{abstract}

Keywords: key performance indicators, plant-wide control, feedback loops.

\section{Introduction}

Feedback is a fundamental concept in automatic control. Feedback loops are used extensively in industrial applications today. The feedback loops are used to assure that the output signal is controlled so that its value approaches the value of the reference signal. In a traditional production plant within the process industry, there can be as many as 1000 feedback loops, each one controlling a single parameter such as a level, a concentration or a temperature. The most frequently used controller is the PID controller. There are methods describing the procedure to create feedback loops. The first step in this method is to select the control parameters (i.e. to think what parameter that should be controlled) and how this value should be measured (i.e. what should be used as measurement signal).

This paper examines how the concept of feedback loops could be used for plant wide control and how key performance indicators could be used as the equivalent to the measurement signal. The paper further gives examples of commonly used key performance indicators and it describes the work that is done within the international standard ISO 22400 [1] [2], currently under development. Further, the requirements for plant wide control are compared with the traditional concepts of automatic control and feedback loops. The first section of the paper describes traditional concepts of automatic control and single parameter feedback loops, the second section discussed plant wide control. Thereafter a presentation of commonly used key performance indicators is given, and a discussion about the similarities of plant-wide control and traditional feedback loops is given. The final section contains the conclusions.

adfa, p. 1, 2011.

(C) Springer-Verlag Berlin Heidelberg 2011 


\section{Single parameter feedback loops}

At production plants in the process industries there are many variables that need to be monitored and controlled. Feedback loops can be used to control these variables. Often, one feedback loops is used to control one variable, e.g. level, temperature or concentration. A feedback loops is shown in Figure 1.

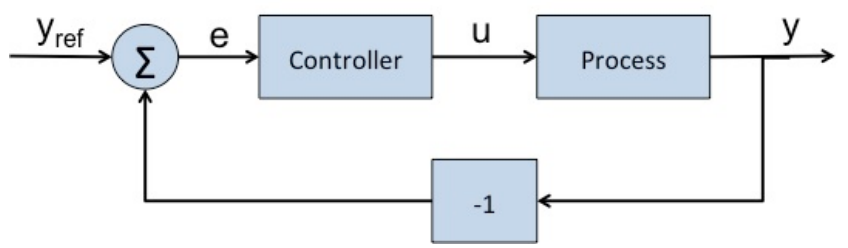

Figure 1: Feedback loop.

Important blocks in the feedback loops are:

- Process: The system that should be controlled, i.e. the system for which you would like to assure that the output is made equal to the reference signal.

- Controller: The task of the controller is to calculate a control signal $u(t)$ based on the control error $\mathrm{e}(\mathrm{t})$ so that the output signal $\mathrm{y}(\mathrm{t})$ approaches and eventually equals the reference signal $\mathrm{y}_{\mathrm{sp}}(\mathrm{t})$.

Important variables in the feedback loops are:

- Reference signal $\mathrm{y}_{\mathrm{sp}}(\mathrm{t})$ : the reference signal is the desired value of the output signal $\mathrm{y}(\mathrm{t})$.

- Control error $\mathrm{e}(\mathrm{t})$ : the input to the controller is the control error e(t), i.e. the difference between the reference signal $\mathrm{y}_{\mathrm{sp}}(\mathrm{t})$ and the output signal $\mathrm{y}(\mathrm{t})$.

- Control signal $u(t)$ : the output of the controller is the control signal $u(t)$, also refered to as the manipulated variable.

- Output signal $y(t)$ : the output signal is the measured value of the output from the process.

The PID controller is by far the most commonly used controller in industry today. There are billions of control loops [3] and the PID controller is used for more than $95 \%$ of all control loops [4]. The PID controller concept is also taught in most introductory automatic control courses, i.e. most control engineers are well aware of the basic principles of feedback. A common work-procedure used when designing traditional single parameter control loops is given in Table 1.

\begin{tabular}{|c|c|}
\hline Step & Activity \\
\hline Step-1 & $\begin{array}{c}\text { select the control-parameter and the corresponding sensors i.e., } \\
\text { select the variable that should be controlled (compare output } \\
\text { signal) and select how it should be measured. }\end{array}$ \\
\hline Step-2 & $\begin{array}{c}\text { select the manipulated-variable and the corresponding actuator, } \\
\text { i.e. select the variable that should be used as control signal and } \\
\text { select how it could be manipulated. }\end{array}$ \\
\hline Step-3 & $\begin{array}{c}\text { construct the control loop, i.e. pair the manipulated-variable } \\
\text { with the control-parameter. }\end{array}$ \\
\hline
\end{tabular}




\begin{tabular}{|c|c|}
\hline Step-4 & $\begin{array}{c}\text { select the type of controller, tune the controller parameters and } \\
\text { search for an optimal set-point. }\end{array}$ \\
\hline
\end{tabular}

Table1: Work procedure used when designing single-parameter control loops.

At production plants in the process industries it is not uncommon to have as many as 1000-10000 variables and about 100-1000 feedback loop at each site. All variables are saved in an historical database. Each feedback loop is of importance for the performance of the plant, however, it is also of importance to get indications of the plant's overall performance. A dilemma is that the single control loops do not have their focus on the overall plant performance but rather on a local part of the plant.

\section{Plant wide control}

An enterprise, having one or more production sites could be structured in a hierarchical fashion. A hierarchy used for this purpose is presented in the international standard IEC 62264 [5] also known as [6], see Figure 2. The term production plant is not explicitly used in this hierarchy and is understood as either a production site or a production area.

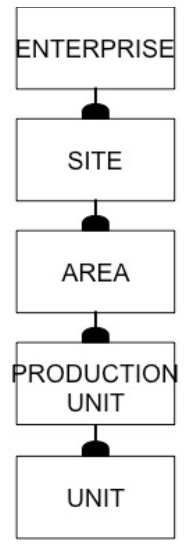

Figure 2: The role based equipment hierarchy of IEC 62264 [5].

According to the role-based equipment hierarchy defined in IEC 62264 [5], an enterprise contains one or more sites, which in turn contains one or more production areas. Each production area has one or more production units and each production unit has one or more units, see Figure 2.

The enterprise determines which products to produce and at which site they should be produced. Sites are usually geographically grouped, and are used for roughcut planning and scheduling. Areas are usually grouped by their geographic location and by their products. Each area produces one or more products, either end products for external sale or intermediates for further use by other areas at the site. Production units generally include all equipment required for a segment of continuous production. A production unit in the process industry could be e.g. a reactor or a distillation column. Units are composed of lower level elements, such as equipment modules, sensors and actuators [7]. At the unit level there might be several single parameter control loops, each one dedicated to control the performance of a single parameter, compare 
Figure 2. The single parameter control loops do not have their focus on the overall plant performance but rather on a local part of the plant.

Step 1 in the work-procedure for single parameter control loops (compare Table 1), is to select the control-parameter and its sensor. In many cases the control-parameter could be measured directly simply by placing a sensor at the correct place. When controlling a production-plant, the selection of a control-parameter might not be as trivial and it might not be possible to direclty, using a single sensor, measure the controlparameter. In many cases, the control-parameter corresponds to an indicator, i.e. a value that itself is calculated from one or many measures in the plant. These indicators are sometimes refered to as key performance indicators (KPIs).

Step 2 in the work-procedure for single parameter control loops (compare Table 1), is to select the manipulated-variable. In many cases the manipulated-variable could be modified simply by introducing an actuator at the correct place. When controlling a production-plant, the selection of a manipulated-variable might not be as trivial and it might not be possible to direclty, using a single actuator, modify the manipulatedvariable.

Step 3 in the work-procedure for single parameter control loops (compare Table 1), is to construct the control loop, i.e. pair the manipulated-variable with the controlparameter. This concept seems reasonable to use also when dealing with plant wide control. Step 4 is to select the type of controller, tune the controller parameters and search for an optimal set-point (compare Table 1). This could be a hard task, however there are known structures for controllers (e.g. PID controller) and known tuning methods (e.g. Ziegler-Nichols or Step responses). When it comes to plant-wide control, this is not as obvious. Today, the correspondance of a plant-wide controller would be the human plant manager or a similar person.

The concept of plant-wide control, could be translated to the concept of classical feedback loops by making the following comparison, the concept is illustrated in Figure 3:

- Controller $=$ plant manager or a similar person

- $\quad$ Process $=$ the complete plant

- $\quad$ Reference signal $=$ the business objective

- $\quad$ Control error $=$ the difference between the business objective and the Key Perofrmance Indicator

- Control-signal = the action taken by the plant manager to assure that the performance of the plant (compare output signal) is approaching and eventually becomes equal to the business objective (compare reference signal).

- Output signal = the key performance indicator. 


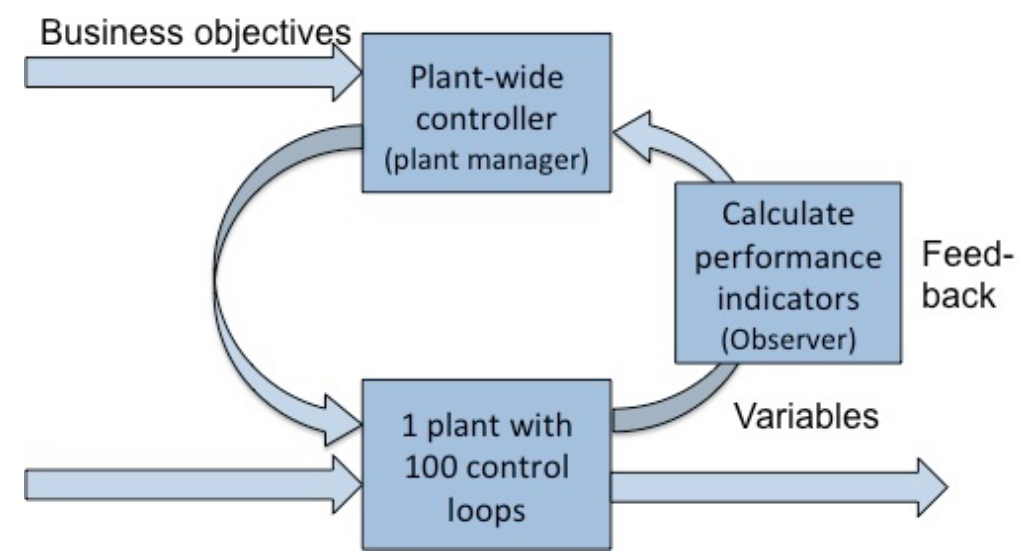

Figure 3: Concept of plant-wide control.

A possible work-procedure for plant-wide control is shown in Table 2.

\begin{tabular}{|c|l|}
\hline Step & \multicolumn{1}{c|}{ Activity } \\
\hline Step-1 & $\begin{array}{l}\text { select the key performance indicator its corresponding definition } \\
\text { i.e., select the indicator that should be controlled (compare output } \\
\text { signal) and find out how it should be calculated. }\end{array}$ \\
\hline Step-2 & $\begin{array}{l}\text { Select "manipulated-indicator", i.e. understands what variables } \\
\text { that should be manipulated in order to make a change in a key } \\
\text { performance indicator in a desired direction. }\end{array}$ \\
\hline Step-3 & $\begin{array}{l}\text { construct the control loop, i.e. pair the manipulated-indicator with } \\
\text { the key-performance indicator. }\end{array}$ \\
\hline Step-4 & $\begin{array}{l}\text { select the "plant-wide controller". This often corresponds to a } \\
\text { human person. It is important to have decision support systems } \\
\text { for this person, so that he or she can take good decisions. The } \\
\text { decisions taken corresponds to the control-signal. }\end{array}$ \\
\hline
\end{tabular}

Table 2: Work procedure used when designing plant-wide control loops.

The development of the international standard ISO 22400 [1] [2] could be seen as an attempt to help defining good key performance indicators (compare good mearurement-variables).

\section{Step1: Key performance indicators}

ISO 22400 is an international standard currently under development. The title is "Key Performance indicators (KPIs) for Manufacturing Operations Management". This work was started in 2009 and the intent is to develop an international standard in 4 parts. ISO22400-Part1 and ISO22400-Part2 are in its final stage and about to be released as International standards.

ISO 22400 defines a Key Performance Indicator as "Quantifiable level of achieving a critical objective" (definition 3.1.4. in ISO 22400-part1). ISO 22400-Part1 [1] 
also states "the KPIs are derived directly from or through an aggregation function of, physical measurements, data and/or other key performance indicators."

ISO 22400 defines a KPI by giving its content and its context.

- Content: a quantifiable element with a specific unit of measure (including the formula that should be used to derive the value of the KPI).

- Context: a verifiable list of conditions that are met.

ISO 22400 should be applicable in both discrete industry and continuous/process industry. The 34 KPIs defined in the standard are listed in Table 3.

\begin{tabular}{|c|c|c|}
\hline Worker Efficiency & Production process ratio & Finished goods ratio \\
\hline Allocation Ratio & $\begin{array}{l}\text { Actual to planned scrap } \\
\text { ratio }\end{array}$ & Integrated goods ratio \\
\hline Throughput rate & First pass yield & Production loss ratio \\
\hline Allocation efficiency & Scrap ratio & $\begin{array}{c}\text { Storage and transportation } \\
\text { loss ratio }\end{array}$ \\
\hline Utilization efficiency & Rework ratio & Other loss ratio \\
\hline $\begin{array}{l}\text { Overall equipment effec- } \\
\text { tiveness index }\end{array}$ & Fall off ratio & Equipment load ratio \\
\hline $\begin{array}{l}\text { Net equipment effective- } \\
\text { ness index }\end{array}$ & Machine capability index & $\begin{array}{l}\text { Mean operating time be- } \\
\text { tween failures }\end{array}$ \\
\hline Availability & $\begin{array}{l}\text { Critical machine capabil- } \\
\text { ity index }\end{array}$ & Mean time to failure \\
\hline Effectiveness & Process capability index & Mean time to restoration \\
\hline Quality Ratio & $\begin{array}{c}\text { Critical process capability } \\
\text { index }\end{array}$ & $\begin{array}{c}\text { Corrective maintenance } \\
\text { ratio }\end{array}$ \\
\hline Setup Rate & $\begin{array}{l}\text { Comprehensive energy } \\
\text { consumption }\end{array}$ & \\
\hline Technical efficiency & Inventory turns & \\
\hline
\end{tabular}

Table 3: A list of the 34 KPIs from the new international standard ISO 22400.

The KPIs defined in ISO22400 are intended to be examples of the most frequently used KPIs in industry today, i.e. a palette of KPIs from which companies can select the one that best corresponds to their business objective. It is recognized that some of the KPIs are better suited for discrete industry and others are better suited for continuous/process industry.

Example: Availability and Utilization efficiency

Two of the 24 KPIs that are defined in ISO 22400-Part2 are Availability and Utilization Efficiency [2]. 
Availability is defined as the Actual-Production-Time (APT) divided by the Planned-Busy-Time (PBT).

- $\quad$ APT: Actual Production Time shall be the time during which a work unit is producing, It includes only the value adding functions.

- PBT: Planned Busy Time shall be the operating time minus the planned downtime.

Utilization Efficiency is defined as Actual-Production-Time (APT) divided by Actual-Unit-Busy-Time (AUBT).

- $\quad$ APT: Actual Production Time shall be the time during which a work unit is producing, It includes only the value adding functions.

- AUBT: Actual Unit Busy Time shall be the actual time that a work unit is used for the execution of a production order.

Availability is thus an indicator of how much of a plant's time that is used for production whereas Utilization efficiency is an indicator of how much of a plant's capacity is utilized. The two concepts are therefore not providing an indication of the same thing.

In discrete industry a machine and/or a plant is often used to its full capacity when it is used, however, it is not unusual that a machine and/or plant is simple waiting for a new job to be assigned. The concept of Availability is therefore frequently used in discrete industries. In continuous/process industry, a unit and/or a plant is often continuously, however it is sometimes used with reduced capacity. The concept of Utilization efficiency is therefore used in continuous industries.

In order to help making the calculations of Availability and Utilization Efficiency, as well as other KPIs, in a consistent way ISO 22400 also contains time models explaining how the measures used in the formulas should be achieved.

\section{End-Example}

The definition of KPIs will help finding good control-parameters in the workprocedure for plant-wide control (Compare step 1 in table 1 and table 2). There is currently nothing in ISO 22400 that has a clear linking to the succeeding steps in the work-procedure for plant-wide control. The work of defining key performance indicators will also be an answer to the industry-wide problem of having "poor visibility into plant operations" and to start utilizing "the hidden resource that data is known to be".

\section{Industry Relevance}

MESA has identified a company as a Business- Mover if the company has improved [8]:

- More than $10 \%$ on one or many of the financial metrics, or

- More than $1 \%$ on over half of the financial metrics.

MESA has further identified that the companies identified as Business-Movers: 
- Have well identified Key Performance Indicators (KPIs),

- Have informed employees, and

- Use IT-systems to get measurements, calculate KPIs and display the results.

This stresses the fact that it is important for a company, interested in controlling and improving the performance of a plant, to understand what control-parameters they have access to (compare Step 1 in Table 1 and Table 2). Future research should also help identifying manipulated-indicators (compare Step-2 in table 1 and Table 2) and suitable control-actions.

\section{Conclusion}

Feedback is a fundamental concept in automatic control. Feedback loops are used extensively in industrial applications today and there are work-procedures for designing traditional single parameter control loops. In the work procedure it is important to select control-parameters, manipulated parameters and control-strategies. A similar work-procedure could also be used for designing plant-wide control feedback loops. The international standard ISO 22400 [1] [2] is helping defining commonly used Key Performance Indicators, these can be used as control-parameters. Future research also needs to focus on how the manipulated-parameters can be selected and how decision support systems can be used for selecting suitable plant wide control strategies.

Acknowledgment: The author C. Johnsson would like to thank the Vinnova-funded research environment LCCC in which environment the author participates, and the PIC-project founded by SSF, Sweden.

\section{References}

[1] ISO/DIS-22400-1 (2013): "Key performance indicators for Manufacturing operations management - Part 1: Overview, Concepts and "International Standardization Organisation (ISO) (draft), 2013.

[2] ISO/DIS-22400-2 (2013): "Key performance indicators for Manufacturing operations management - Part 2: Definitions and descriptions. International Standardization Organisation (ISO) (draft), 2013.

[3] Soltesz, K. (2012). On automation of the PID tuning procedure. Licentiate Thesis ISRN LUTFD2/TFRT--3254--SE, Department of Automatic Control, Lund University, Sweden.

[4] Åström, K. and Murray, R. (2012): "Feedback Systems: An Introduction for Scientists and Engineers", Princeton University Press, Princeton and Oxford. URL http:// www.cds.caltech.edu/ murray/amwiki

[5] IEC 62264 (2003): "Enterprise-Control System Integration, Part 1 Models and terminology", International Elechtrotechnical Commission (IEC).

[6] ISA-95.00.01 (2009): "Enterprise-Control System Integration, Part 1: Models and Terminology", International Society of Automation (ISA), 2009.

[7] Lindholm A., and Johnsson C. (2012): "A tool for utility disturbance management, presented at INCOM 2012.

[8] MESA (2006): "Metrics that Matters", Manufacturing Enterprise Solutions Association (MESA), report of 2006 